\section{Commentary: There's always something new around the next bend}

\author{
Richard D. Mainwaring, MD
}

I would like to congratulate Grau and colleagues ${ }^{1}$ for an excellent article and video focusing on the technique of reimplantation for anomalous right coronary artery. This surgical technique has enjoyed a rise in popularity in recent years and has now been reported by multiple groups. $^{2-4}$ The authors demonstrate that reimplantation is a relatively straightforward procedure utilizing methods quite similar to a proximal coronary artery bypass anastomosis. I agree that this is a straightforward surgical technique.

What is not clearly articulated in this article is why one would feel compelled to change from the previously in vogue procedure of unroofing to the now in vogue procedure of reimplantation. Was there a problem with the unroofing procedure that led to this change? The short answer is-not really. Among the purported issues with the unroofing procedure was the development of new aortic valve insufficiency. However, most surgeons quickly learned about the fragility of the valve commissure and stopped performing maneuvers that would destabilize the commissure. Congenital Heart Surgeons' Society study data show that patients who had no procedure on the commissure may develop new aortic valve insufficiency-presumably related to performing an aortotomy and subsequent distortion upon closure of the aorta. ${ }^{5}$ It should be noted that the current article still advocates for performing an aortotomy.

\footnotetext{
From the Division of Pediatric Cardiac Surgery, Stanford University School of Medicine, Lucile Packard Children's Hospital at Stanford, Stanford, Calif. Disclosures: The author reported no conflicts of interest.

The Journal policy requires editors and reviewers to disclose conflicts of interest and to decline handling or reviewing manuscripts for which they may have a conflict of interest. The editors and reviewers of this article have no conflicts of interest.

Received for publication Feb 2, 2021; revisions received Feb 2, 2021; accepted for publication Feb 4, 2021; available ahead of print Feb 8, 2021.

Address for reprints: Richard D. Mainwaring, MD, Division of Pediatric Cardiac Surgery, Stanford University School of Medicine, 300 Pasteur Dr, Falk CVRC, Stanford, CA 94305 (E-mail: mainwaring@stanford.edu).

JTCVS Techniques 2021;7:229-30

2666-2507

Copyright (C) 2021 The Authors. Published by Elsevier Inc. on behalf of The American Association for Thoracic Surgery. This is an open access article under the CC BY-NCND license (http://creativecommons.org/licenses/by-nc-nd/4.0/).

https://doi.org/10.1016/j.xjtc.2021.02.010
}

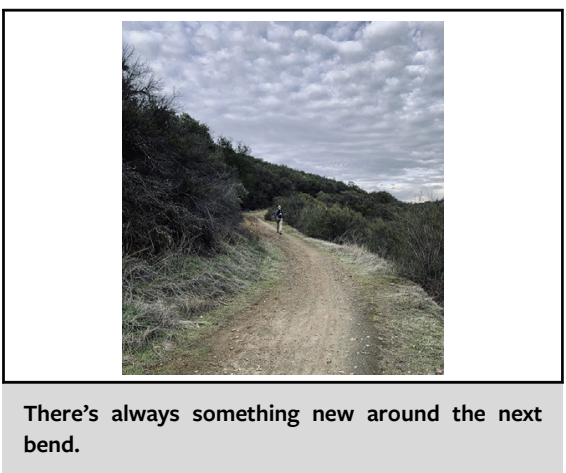

CENTRAL MESSAGE

There's always something new around the next bend, but that does not mean that it will necessarily be better.

Among the issues that our group noted following unroofing procedures was a small but noticeable incidence of recurrent symptoms. ${ }^{6}$ To be specific, this occurred in just 3 of 130 patients (ie, $2.2 \%$ ) who had undergone an unroofing procedure. Two of these patients had undergone a short unroofing procedure and presumably failed because the neo-ostia was not moved far enough away from the commissure. The third patient developed recurrent, intermittent chest pain that was eventually attributed to a myocardial bridge. For these 3 patients, the interval between their unroofing procedure and their reoperation was 5, 5, and 7 years. Conversely, $97.8 \%$ of the patients underwent an unroofing procedure without mortality or recurrence of symptoms with an average follow-up of more than 5 years. The takeaway message is that there was a very low incidence of failures that invariably had an anatomic basis and it took many years for the failures to surface.

The field of congenital heart surgery is exciting because there's always something new around the next bend (Figure 1). However, just because something is new doesn't necessarily mean it is better. The transition from unroofing to coronary reimplantation is a transition from 1 relatively straightforward procedure to another. Given the very low incidence of mortality/recurrent symptoms following unroofing, it is doubtful that this new, in vogue procedure could ever be shown to be superior from a statistical standpoint. 


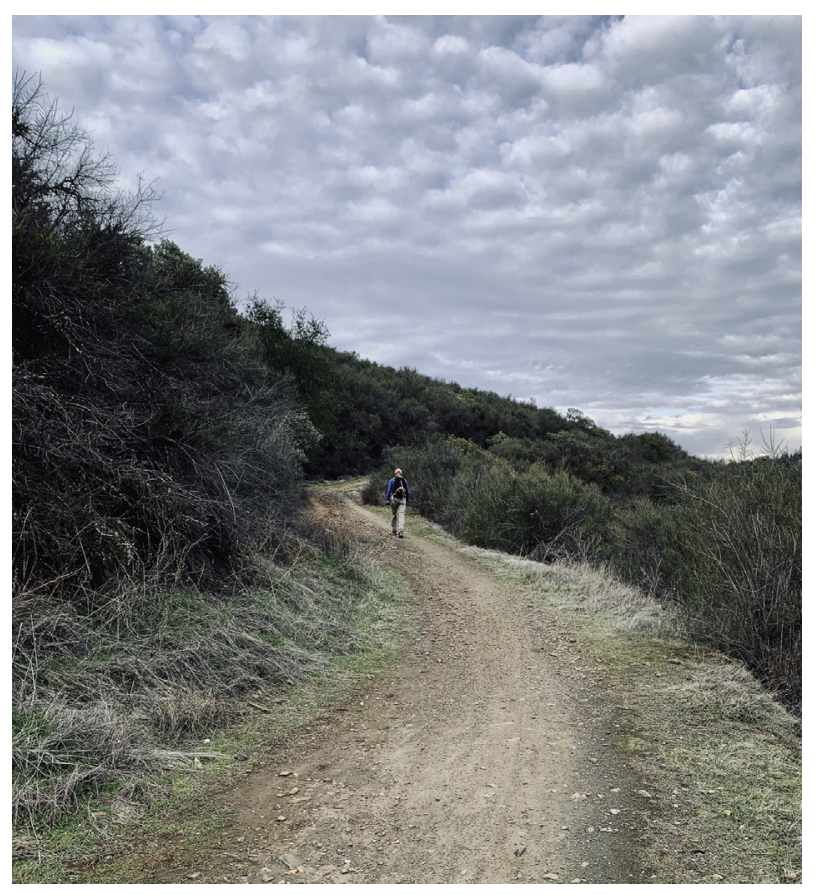

FIGURE 1. There's always something new around the next bend-photograph of the Salmon Falls Trail, Auburn, Calif.

\section{References}

1. Grau JB, Rahmouni K, Castillo J, Ruel M, Maharajh G. Reimplantation for anomalous right coronary artery. J Thorac Cardiovasc Surg Tech. 2021;7:226-8.

2. Izumi K, Wilbring M, Stumpf J, Matschke K, Kappert U. Direct reimplantation as an alternative approach for treatment of anomalous aortic origin of the right coronary artery. Ann Thorac Surg. 2014;98:740-2.

3. Law T, Dunne B, Stamp N, Ho KM, Andrews D. Surgical results and outcomes after reimplantation for the management of anomalous aortic origin of the right coronary artery. Ann Thorac Surg. 2016;102:192-9.

4. Cubero A, Crespo A, Hamzeh G, Cortes A, Rivas D, Aramendi JI. Aortic origin of the right coronary artery from the left coronary sinus - 13 cases treated with the reimplantation technique. World J Pediatr Congenit Heart Surg. 2017;8:315-20.

5. Jegatheeswaran A, Devlin PJ, Williams WG, Brothers JA, Jacobs ML, DeCampli WM, et al. Outcomes after anomalous aortic origin of a coronary artery repair: a Congenital Heart Surgeons' Society study. J Thor Cardiovasc Surg. 2020; 160:757-69.

6. Mainwaring RD, Murphy DJ, Rogers IS, Chan FP, Petrossian E, Palmon M, et al. Surgical repair of 115 patients with anomalous aortic origin of a coronary artery. World J Pediatr Congenit Heart Surg. 2016;7:353-9. 